\title{
Association of subclinical hypothyroidism with metabolic syndrome in females of reproductive age
}

\begin{tabular}{c}
\hline Muhammad Sadradin Mahmood ${ }^{1 *} \quad$ Yousif Bahaaddin Ahmed $^{1}$ \\
\hline Abstract $^{2}$
\end{tabular}

Background and objective: The association of metabolic syndrome and subclinical hypothyroidism is a matter of debate. Both confer an increased risk for cardiovascular disease and type 2 diabetes mellitus, and previous studies showed overlap between features of both conditions. This study aimed to evaluate the association of subclinical hypothyroidism with metabolic syndrome in young women.

Methods: This case control study was conducted in the internal medicine consultation department of Rizgary Teaching Hospital Erbil, Iraq, from May 2017 to May 2018. Sixty eight consecutive women with the metabolic syndrome as per the Harmonizing definition were compared to 95 age matched women with no metabolic syndrome as a control group. Detailed history and physical examination with blood pressure and waist circumferences recorded and appropriate fasting blood samples were tested for plasma glucose, lipid profile, TSH, free T3, and free T4.

Results: Subclinical hypothyroidism was present in $10(14.7 \%)$ of the 68 women with metabolic syndrome and four women $(4.2 \%)$ of the 95 control group with a significant difference $(P=0.018)$. Central obesity, hypertriglyceridemia, and low levels of high density lipoprotein were present in $9(17.3 \%), 9(23.1 \%)$, and $10(16.4 \%)$ women with subclinical hypothyroidism with a significant difference for each association $(P=0.013,0.001$ and 0.006 , respectively).

Conclusion: There is a significant association between subclinical hypothyroidism and metabolic syndrome in young women.

Keywords: Metabolic syndrome; Subclinical hypothyroidism; Young women.

\section{Introduction}

Background: The metabolic syndrome (MetS), previously called syndrome $\mathrm{X}$ or Insulin resistance syndrome, consists of a group of traits that confers increased risk to cardiovascular disease and type 2 diabetes mellitus. Though the pathogenesis is poorly understood, insulin resistance is its primary pathophysiological derangement, among others, and its most characteristic features are obesity as measured by waist circumference, hyperglycemia, hypertension and dyslipidemia. ${ }^{1}$ On the other hand, subclinical hypothyroidism ( $\mathrm{SCH}$ ), which is a laboratory diagnosis defined as a normal serum free $\mathrm{T} 4$ with an elevated $\mathrm{TSH}^{2,3}$ is also associated with increased risk for cardiovascular disease. ${ }^{4}$ Thus, the presence of both these two conditions in a patient may further increase the risk of cardiovascular disease. Inflammation, which is a feature of the metabolic syndrome as evident by increased concentration of the highly sensitive $c$ reactive protein, and cytokine levels like IL6, IL1, and TNFa, is also found in patients with subclinical hypothyroidism. ${ }^{5}$ A relationship has been found between subclinical hypothyroidism and many of the components of metabolic syndrome such as insulin resistance, central obesity, dyslipidemia, hyperglycemia, and hypertension. This indicates a great degree

${ }^{1}$ Department of I nternal Medicine, College of Medicine, Hawler Medical University, Erbil, I raq.

* Correspondence: dr_sadradin@yahoo.com 
of overlaps between the two conditions. ${ }^{6}$ The prevalence of metabolic syndrome is increasing ${ }^{7,8}$ and this was especially more in women. ${ }^{9}$ The prevalence of subclinical hypothyroidism according to population based studies ranges from 4-15 percent; it rises with age and is higher in women. ${ }^{10-12}$ Several studies have found an association between subclinical hypothyroidism and the metabolic syndrome ${ }^{13-17}$ and some have not. ${ }^{18,19}$ The results are conflicting somewhat and none of these studies studied the association exclusively in young women. Therefore, we felt the need to explore the association in such specific group of women, especially if we consider that both metabolic syndrome and subclinical hypothyroidism are pre-morbid conditions and the earlier and the younger the patients are discovered may be better in order to start preventive measures to decrease progression to cardiovascular disease and type 2 diabetes mellitus. To our knowledge, no studies have been done to address this association in our locality. It is important to find this association as both metabolic syndrome and subclinical hypothyroidism may increase the cardiovascular risk of a given patient further if they co-existed. We aimed primarily at studying the association between subclinical hypothyroidism and metabolic syndrome in women of reproductive age as both conditions are more common in women, and few such studies had addressed this association in women even globally. Our secondary aim was to correlate subclinical hypothyroidism with different components of the metabolic syndrome namely central obesity, fasting blood sugar, systolic and diastolic blood pressure, high serum triglyceride and low high density lipoprotein cholesterol

\section{Methods}

This was a case control study. Consecutive female patients presented to the Internal Medicine Outpatient clinic at Rizgary Teaching Hospital in Erbil Iraq aged 18-45 years were investigated for metabolic syndrome from May 2017 to May 2018. A total of 68 women with metabolic syndrome were included in this study, and 95 age matched women included as a control group. Metabolic syndrome was diagnosed as per the harmonizing definition $^{20}$ of the metabolic syndrome i.e. any 3 out of the 5 criteria of waist circumference $>80 \mathrm{~cm}$, fasting TG $\geq 150$ $\mathrm{mg} / \mathrm{dl}$, HDL-C $<50 \mathrm{mg} / \mathrm{dl}$, BP $\geq 130 \mathrm{mmHg}$ systolic or $\geq 85 \mathrm{mmHg}$ diastolic, fasting plasma glucose level $\geq 100 \mathrm{mg} / \mathrm{dl}$. Waist circumference was measured by a tape measure at mid-level between the superior iliac crest and the lower costal margin in standing position. Blood pressure was measured using a standard mercury sphygmomanometer in the sitting position. Appropriate blood samples were collected for fasting blood glucose, lipid profile, and TSH and free T4 and T3 after 8 hours of fasting. Serum TSH, free T4, and free T3 were measured by the electrochemiluminescence immunoassay (ECLIA) on Elecys and Cobas e immunoassay analyzers Roche/Hitachi. Fasting blood cholesterol, TG, HDL, and LDL were measured by the enzymatic colorimetric method for Cobas c 311/501 automatic analyzers Roche/Hitachi. Fasting blood sugar was measured by enzymatic reference method with hexokinase for Cobas c 311/501 analyzers Roche/Hitachi. The reference range for TSH was $0.27-4.2 \mu \mathrm{lU} / \mathrm{ml}$, that for free T4 was $12-22 \mathrm{pmol} / \mathrm{L}$, and that for free T3 was 3.1-6.8 pmol/L. Subclinical hypothyroidism was defined as TSH higher than the reference range with normal free $\mathrm{T} 4$ and free T3. A detailed history and physical examination were carried out. Those who were pregnant had overt diabetes mellitus, menopausal or had known thyroid disease, chronic liver or renal diseases, or taking any medications like contraceptive pills or steroids or any other medications that were known to affect thyroid function were excluded. Control cases had 0 of the 5 criteria of the harmonizing definition of the metabolic syndrome. Data were entered 
into the statistical package for the social science (version 21) to carry out statistical analysis. The means for continuous variables were compared using independent two sample $t$ test and Chi-square test for the qualitative variables. A $P$ value of $\leq 0.05$ was considered as statistically significant. Five patients had thyroid dysfunction on testing other than subclinical hypothyroidism were excluded.

\section{Ethical considerations}

This study was approved by the ethical committee of the College of Medicine, Hawler Medical University. Verbal consent was obtained from every patient and case in this study after a careful explanation of the study and the procedures.

\section{Results}

A total of 163 women were included in this study. Of these, 68 women $(41.7 \%)$ with a mean age of (35.8 years $\pm 6.8 \mathrm{SD}$ ) had metabolic syndrome and 95 women $(58.2 \%)$ with a mean age of (35.6 years \pm 6.8 SD) had no metabolic syndrome served as a control group. The basic characteristics of the study group are shown in Table 1.

Table 1: Basic characteristics of the study population.

\begin{tabular}{lccc}
\hline & $\begin{array}{c}\text { MetS Group* } \\
(\mathbf{n}=68) \\
\text { Means } \pm \text { SD }\end{array}$ & $\begin{array}{c}\text { Control Group } \\
(\mathbf{n}=95) \\
\text { Means } \pm \text { SD }\end{array}$ & P value \\
\hline Age (years) & $35.8 \pm 6.8$ & $35.6 \pm 6.8$ & 0.87 \\
Waist circumference (centimeters) & $91 \pm 14.9$ & $72.2 \pm 4.2$ & $<0.0001$ \\
Systolic BP (mmHg) & $118.4 \pm 16.6$ & $99.4 \pm 12.5$ & $<0.0001$ \\
Diastolic Bp (mmHg) & $78.1 \pm 16.1$ & $67.4 \pm 9.7$ & $<0.0001$ \\
Fasting Plasma Glucose( mg/dl) & $100.8 \pm 56.5$ & $77.1 \pm 14.3$ & $<0.002$ \\
Serum Triglyceride (mg/dl) & $172.6 \pm 65.7$ & $70.9 \pm 26.7$ & $<0.0001$ \\
Serum High Density Lipoprotein (mg/dl) & $39 \pm 8.6$ & $56.9 \pm 7.8$ & $<0.0001$ \\
Serum total Cholesterol (mg/dl) & $168.4 \pm 36$ & $146.8 \pm 31.4$ & $<0.0001$ \\
Serum LDL (mg/dl) & $105.1 \pm 34.1$ & $88.5 \pm 28.1$ & $<0.001$ \\
Serum TSH ( $\mu$ lU/ml) & $2.4 \pm 1.5$ & $2 \pm 1$ & 0.063 \\
Serum fT3 (pmol/L) & $5.9 \pm 6.1$ & $5.7 \pm 4$ & 0.854 \\
Serum fT4 ( pmol/L) & $14.8 \pm 2.7$ & $15.6 \pm 2.1$ & $<0.05$ \\
\hline Metabolic syndrome. & & & \\
\hline
\end{tabular}


Of the total 163 women, subclinical hypothyroidism $(\mathrm{SCH})$ was present in 14 women, with an overall prevalence of $8.5 \%$ in the study population. SCH was present in 10 women $(14.7 \%)$ of the metabolic syndrome group and four women $(4.2 \%)$ of the control group with a significant $P$ value of 0.018 , as shown in Figure 1. Central obesity was present in 9 (17.3\%) women with $\mathrm{SCH}$ and absent in the remaining $5(4.5 \%)$ patients with $\mathrm{SCH}$, and the $P$ value of 0.013 denoted a significant association, as shown in Table 2.

Table 2: Association of $\mathrm{SCH}$ with components of the metabolic syndrome.

\begin{tabular}{lccccc}
\hline \multirow{2}{l}{$\begin{array}{l}\text { Components of the metabolic } \\
\text { syndrome }\end{array}$} & \multicolumn{2}{c}{$\begin{array}{c}\text { Subclinical Hypothyroidism } \\
\text { Present }\end{array}$} & Absent & Total & P value \\
\hline Central obesity & Present & $9(17.3 \%)$ & $43(82.7 \%)$ & $52(100 \%)$ & 0.013 \\
& Absent & $5(4.5 \%)$ & $106(95.5 \%)$ & $111(100 \%)$ & \\
& & & & $163(100 \%)$ & \\
Hypertriglyceridemia & Present & $9(23.1 \%)$ & $30(76.9 \%)$ & $39(100 \%)$ & 0.001 \\
& Absent & $5(4 \%)$ & $119(96 \%)$ & $124(100 \%)$ & \\
Low HDL & & & & $163(100 \%)$ & \\
& Present & $10(16.4 \%)$ & $51(83.6 \%)$ & $61(100 \%)$ & 0.006 \\
& Absent & $4(3.9 \%)$ & $98(96.1 \%)$ & $102(100 \%)$ & \\
Hyperglycemia & & & & $163(100 \%)$ & \\
& Present & $1(3.6 \%)$ & $27(96.4 \%)$ & $28(100 \%)$ & 0.4 \\
& Absent & $13(9.6 \%)$ & $122(90.4 \%)$ & $135(100 \%)$ & \\
Systolic Hypertension & Present & $0(0.0 \%)$ & $9(100 \%)$ & $9(100 \%)$ & 1 \\
& Absent & $14(9.1 \%)$ & $140(90 \%)$ & $154(100 \%)$ & \\
& & & & $163(100 \%)$ & \\
Diastolic Hypertension & Present & $2(8.3 \%)$ & $22(91.7 \%)$ & $24(100 \%)$ & 1 \\
& Absent & $12(8.6 \%)$ & $127(91.4 \%)$ & $139(100 \%)$ & \\
& & & & $163(100 \%)$ & \\
\hline
\end{tabular}

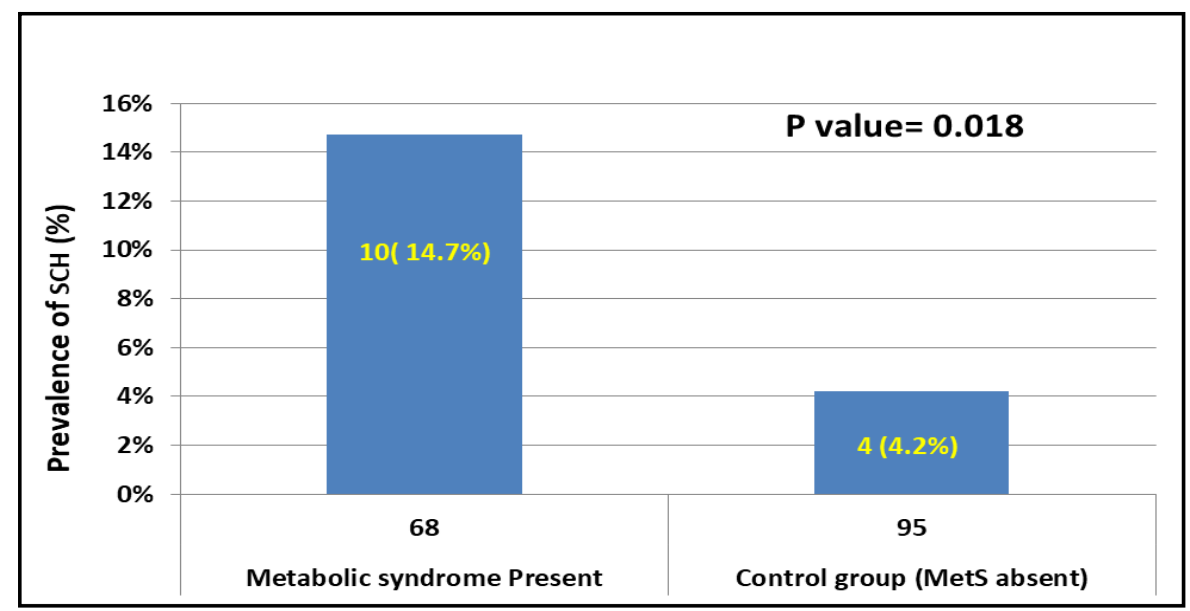

Figure 1: Prevalence of $\mathrm{SCH}$ in Metabolic syndrome versus control group. 
We also found a significant association between $\mathrm{SCH}$ and hypertriglyceridemia, which was present in $9(23.1 \%)$ women and absent in $5(4 \%)$ women with $\mathrm{SCH}$ with a $P$ value of 0.001 , as shown in Table 2 . Low HDL was present in 10 (16.4\%) women with $\mathrm{SCH}$ and absent in 4 (3.9\%) women with a significant $P$ value at 0.006 , as shown in Table 2. The association of $\mathrm{SCH}$ with other components of metabolic syndrome, namely hyperglycemia, systolic hypertension, and diastolic hypertension were not significant, as shown in Table 2 . The mean serum total cholesterol and LDL in the 14 women with $\mathrm{SCH}$ were $162.5 \pm$ $44.5 \mathrm{SD} \mathrm{mg} / \mathrm{dl}$ and $108.5 \pm 46.2 \mathrm{SD} \mathrm{mg} / \mathrm{dl}$ compared to $155.2 \pm 34 \mathrm{SD} \mathrm{mg} / \mathrm{dl}$ and 94.2 $\pm 29.9 \mathrm{SD} \mathrm{mg} / \mathrm{dl}$ in the 149 women with no $\mathrm{SCH}$ with insignificant $P$ values of 0.55 and 0.27 respectively.

\section{Discussion}

We found a significant association between $\mathrm{SCH}$ and metabolic syndrome in our study. This finding is consistent with a number of other studies ${ }^{13-17,21-24}$ and contrasts with what found by some others. ${ }^{18,19,25}$ Actually, there is much evidence with the association and little evidence against it though the association is still a matter of debate. This association is thought to be due to possible common pathophysiology of insulin resistance, inflammation and TSH receptor resistance. ${ }^{6}$ Gupta et al. ${ }^{21}$ has found a strong association between subclinical hypothyroidism and metabolic syndrome in a cross sectional study in a rural tertiary hospital in India. He compared the association in 60 patients with metabolic syndrome, diagnosed as per IDF criteria, and 120 controls with a mean age of 47 years. Subclinical hypothyroidism was found in $58 \%$ of the metabolic syndrome group compared to $14 \%$ in the control group. Senthil et al. ${ }^{22}$ studied the prevalence of thyroid dysfunction in 300 patients with metabolic syndrome, diagnosed as per IDF criteria, of which 134 patients were females. He found that subclinical hypothyroidism was the most common thyroid abnormality, and it was found in 113 patients (38\%) of the study group and accounted for $70 \%$ of thyroid abnormalities observed. Of note is that only $20 \%$ of the females in this study were in the age group of $31-40$ years. Gyawali et al. $^{23}$ also studied the pattern of thyroid dysfunction in patients with metabolic syndrome in a cross sectional case control study. Diagnosis of metabolic syndrome was made as per NCEP: ATP III criteria with waist circumference adjusted for Asians. He included 358 patients with metabolic syndrome and 341 patients as a control group. Of the metabolic syndrome group, 232 were females. He found that subclinical hypothyroidism was significantly associated with metabolic syndrome being present in $29 \%$ of patients in the metabolic syndrome group compared to $4 \%$ in the control group. Of those with subclinical hypothyroidism in the study group, $67 \%$ were females, so he concluded that subclinical hypothyroidism is high in patients with metabolic syndrome, especially in women, and he demanded to test routine for thyroid function in metabolic syndrome patients. On the other hand, Wang et al., ${ }^{18}$ Garduño-Garcia et al., ${ }^{19}$ and Lai et al. ${ }^{25}$ did not find a significant association between $\mathrm{SCH}$ and metabolic syndrome in Taiwanese and Mexican people. Of note, their patients included both sexes, and their mean ages were above 50,42 , and 65 years, respectively. Differences in our patient's characters, especially being young women, may explain the differences in our results compared to theirs. We also found a significant association between $\mathrm{SCH}$ and some components of metabolic syndrome, namely central obesity, hypertriglyceridemia, and low HDL but not with systolic or diastolic hypertension neither with hyperglycemia. Association between $\mathrm{SCH}$ and different components of metabolic syndrome was found in several other studies ${ }^{16,21,24}$ and was not found by others. ${ }^{18,23,25}$ Pangaluri et al. ${ }^{16}$ found that women with $\mathrm{SCH}$ had higher triglycerides 
(26.6\%) and lower HDL (30\%). Khatiwada et al. ${ }^{24}$ have found that that waist circumference had a significant difference in patients with or without thyroid dysfunction, and HDL-C did correlate negatively with $\mathrm{TSH}$ levels. Our findings go with the above associations. The inconsistencies observed in association of $\mathrm{SCH}$ with components of metabolic syndrome may be due to different patient's characters from the start and include differences in definitions applied for the metabolic syndrome diagnosis and study designs. We depended on the harmonizing definition for diagnosing metabolic syndrome, which includes but does not necessitate central obesity as a criterion. However, we still found a strong association between central obesity and $\mathrm{SCH}$. This may reflect the importance of central obesity and its relation to insulin resistance as one of the important pathophysiological changes that occur in metabolic syndrome. Actually, only 16 $(23.6 \%)$ out of the 68 women with metabolic syndrome had no central obesity, and $5(35.71 \%)$ women out of 14 with $\mathrm{SCH}$ had no central obesity. Lastly, the prevalence of $\mathrm{SCH}$ in our study population was $8.5 \%$, which is comparable to the global prevalence of this condition that ranges from 4-15 percent or even higher. $^{10-12}$

\section{Conclusion}

There is a significant association between subclinical hypothyroidism and metabolic syndrome, and some of its components like central obesity, high triglyceride levels, and low high density lipoprotein levels in young women of reproductive age.

\section{Competing interests}

The authors declare no competing interests.

\section{References}

1. Eckel RH. The metabolic syndrome. In: Kasper DL, Fauci AS, Haucer SL, Longo DL, Jameson $\mathrm{JL}$, Loscalzo J (editors). Harrison's principles of internal medicine. $19^{\text {th }}$ ed. New York: McGraw-Hill
Education; 2015. P. 2449-54.

2. Biondi B, Cooper DS. The clinical significance of subclinical thyroid dysfunction. Endocr Rev 2008; 29:76.

3. Cooper DS, Biondi B. Subclinical thyroid disease. Lancet 2012; 379:1142.

4. Rodondi N, den Elzen WP, Bauer DC, Cappola AR, Razvi S, Walsh JP, et al. Subclinical hypothyroidism and the risk of coronary heart disease and mortality. JAMA 2010; 304:1365.

5. Kvetny J, Heldgaard PE, Bladbjerg EM, Gram J. Subclinical hypothyroidism is associated with a low-grade inflammation, increased triglyceride levels and predicts cardiovascular disease in males below 50 years. Clin Endocrinol (Oxf) 2004; 61:232.

6. Waring AC, Rodondi N, Harrison S, Kanaya AM, Simonsick EM, Miljkovic I, et al. Thyroid function and prevalent and incident metabolic syndrome in older adults: the health, ageing and body composition study. Clin Endocrinol (Oxf) 2012; 76: 911-8.

7. Ford ES. Prevalence of the metabolic syndrome defined by the International Diabetes Federation among adults in the U.S. Diabetes Care 2005; 28:2745.

8. Ford ES, Giles WH, Dietz WH. Prevalence of the metabolic syndrome among US adults: findings from the third National Health and Nutrition Examination Survey. JAMA 2002; 287:356.

9. Ford ES, Giles WH, Mokdad AH. Increasing prevalence of the metabolic syndrome among US adults. Diabetes Care 2004; 27:2444.

10. Bagchi N, Brown TR, Parish RF. Thyroid dysfunction in adults over age 55 years. A study in an urban US community. Arch Intern Med 1990; $150: 785$.

11. Kanaya AM, Harris F, Volpato S, Pérez-Stable EJ, Harris T, Bauer DC. Association between thyroid dysfunction and total cholesterol level in an older biracial population: the health, aging and body composition study. Arch Intern Med 2002; 162:773.

12. Canaris GJ, Manowitz NR, Mayor G, Ridgway EC. The Colorado thyroid disease prevalence study. Arch Intern Med 2000; 160:526.

13. Uzunlulu M, Yorulmaz E, Oguz A. Prevalence of subclinical hypothyroidism in patients with metabolic syndrome. Endocr J 2007; 54(1):71-6.

14. Kota SK, Meher LK, Krishna S, Modi K. Hypothyroidism in metabolic syndrome. Indian $\mathrm{J}$ Endocrinol Metab 2012; 16(Suppl 2):S332-3.

15. Chugh K, Goyal S, Shankar V, Chugh SN. Thyroid function tests in metabolic syndrome. Indian J Endocrinol Metab 2012; 16(6):958-61.

16. Pangaluri R, Akila S, William E. Prevalence of metabolic syndrome and its components in women with subclinical hypothyroidism. Asian J Pharm Clin Res 2013; 6(4):82-4.

17. Khan S, Afsana F, Talukder SK, Ashrafuzzaman SM, Pathan F, Latif ZA. Presence and 
association of sub clinical hypothyroidism in subjects with metabolic syndrome. Diabetes Metab Syndr 2011; 5(4):183-7.

18. Wang CY, Chang TC, Chen MF. Associations between subclinical thyroid disease and metabolic syndrome. Endocr J 2012; 59(10):9117.

19. Garduño-Garcia J, Alvirde-Garcia U, LópezCarrasco G, Padilla Mendoza ME, Mehta R, Arellano-Campos $\mathrm{O}$, et al. TSH and free thyroxine concentrations are associated with differing metabolic markers in euthyroid subjects. Eur $\mathrm{J}$ Endocrinol 2010; 163(2):273-8.

20 .Alberti KG, Eckel RH, Grundy SM, Zimmet PZ, Cleeman JI, Donato KA, et al. Harmonizing the metabolic syndrome: a joint interim statement of the International Diabetes Federation Task Force on Epidemiology and Prevention; National Heart, Lung, and Blood Institute; American Heart Association; World Heart Federation; International Atherosclerosis Society; and International Association for the Study of Obesity. Circulation 2009; 120:1640.

21. Gupta HR, Sheth SP, Vaishnav BS. Association of subclinical hypothyroidism with metabolic syndrome: Across sectional study in western India. Asian J Pharm Clin Res 2016; 9(4):265-9.

22. Senthil N, Thomas S, Santosh P, Sujatha. S. A study of prevalence of thyroid dysfunction in patients with metabolic syndrome. Int J Res Med Sci 2015; 3(11):3171-76.

23. Gyawali P, Takanche JS, Shrestha1 RK, Bhattarai P, Khanal K, Risal P, et al. Pattern of thyroid dysfunction in patients with metabolic syndrome and its relationship with components of metabolic syndrome. Diabetes Metab J 2015; 39:66-73.

24. Khatiwada S, Sah KS, Rajendra KC, Baral N, Lamsal M. Thyroid dysfunction in metabolic syndrome patients and its relationship with components of metabolic syndrome. Clin Diabetes Endocrinol 2016; 2:3.

25. Lai CC, Tang SH, Pei D, Wang CY, Chen YL, Wu $\mathrm{CZ}$, et al. The prevalence of subclinical thyroid dysfunction and its association with metabolic syndrome in Taiwanese elderly. Int J Gerontol 2011; 5:25-9. 